Supplement of Atmos. Chem. Phys. Discuss., 15, 34719-34763, 2015

http://www.atmos-chem-phys-discuss.net/15/34719/2015/

doi:10.5194/acpd-15-34719-2015-supplement

(C) Author(s) 2015. CC Attribution 3.0 License.

(c) (i)

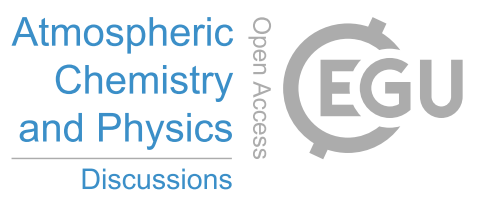

Supplement of

\title{
The importance of vehicle emissions as a source of atmospheric ammonia in the megacity of Shanghai
}

\section{Y. H. Chang et al.}

Correspondence to: C. R. Deng (congruideng@ fudan.edu.cn) and G. S. Zhuang (gzhuang@ fudan.edu.cn)

The copyright of individual parts of the supplement might differ from the CC-BY 3.0 licence. 


\section{This file includes:}

\section{Figures}

Fig. S1 Comparison of results obtained with the Ogawa $\mathrm{NH}_{3}$ PSDs and an active monitor (MARGA) at Pudong supersite from May 2014 to June 2015.

Fig. S2 RH/T dependence of $\mathrm{NH}_{3}$ concentration in spring (a), summer (b), fall (c), and winter (d) at Pudong supersite during April 2, 2014-April 3, 2015.

Fig. S3 WS/WD dependence of $\mathrm{NH}_{3}$ concentrations in spring (a), summer (b), fall (c), and winter (d) at Pudong supersite during April 2, 2014-April 3, 2015.

\section{Table}

Table S1. Descriptive statistics of the $\mathrm{NH}_{3}$ concentration $\left(\mu \mathrm{g} \mathrm{m}^{-3}\right)$ at different sampling sites in and out of the Handan tunnel during the spring campaign in 2014. See Figure 7a and the method section for the information on the sampling points 


\section{Figures}

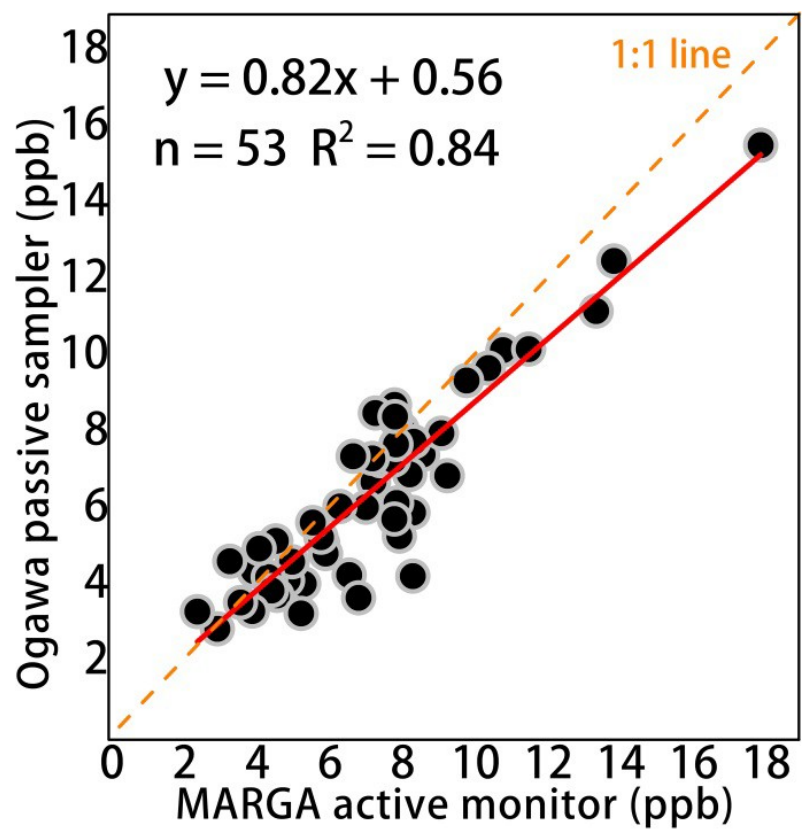

Figure S1. Comparison of results obtained with the Ogawa $\mathrm{NH}_{3} \mathrm{PSDs}$ and an active monitor (MARGA) at Pudong supersite from May 2014 to June 2015. 

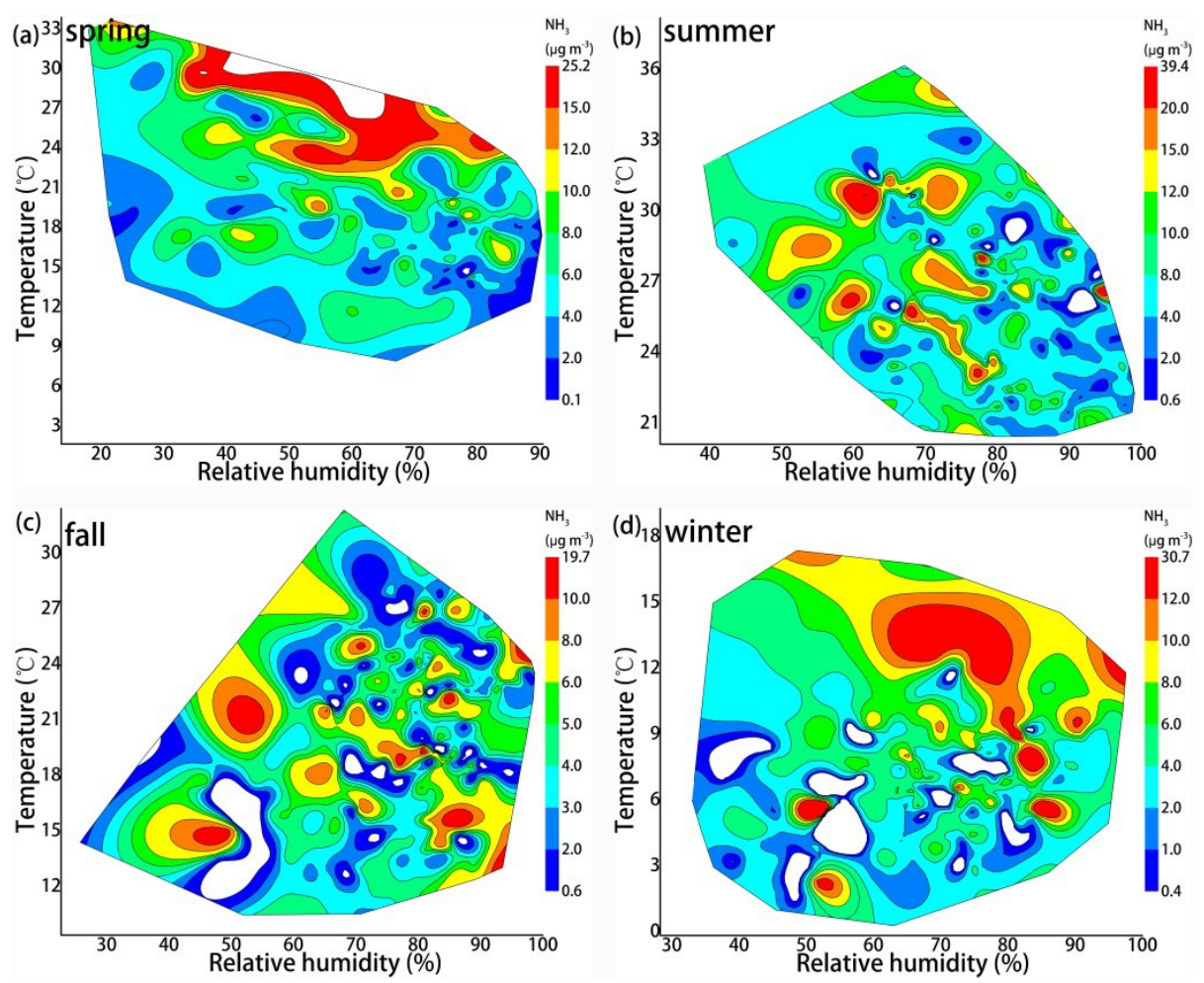

Figure S2. RH/T dependence of $\mathrm{NH}_{3}$ concentration in spring (a), summer (b), fall (c), and winter (d) at Pudong supersite during April 2, 2014-April 3, 2015. 

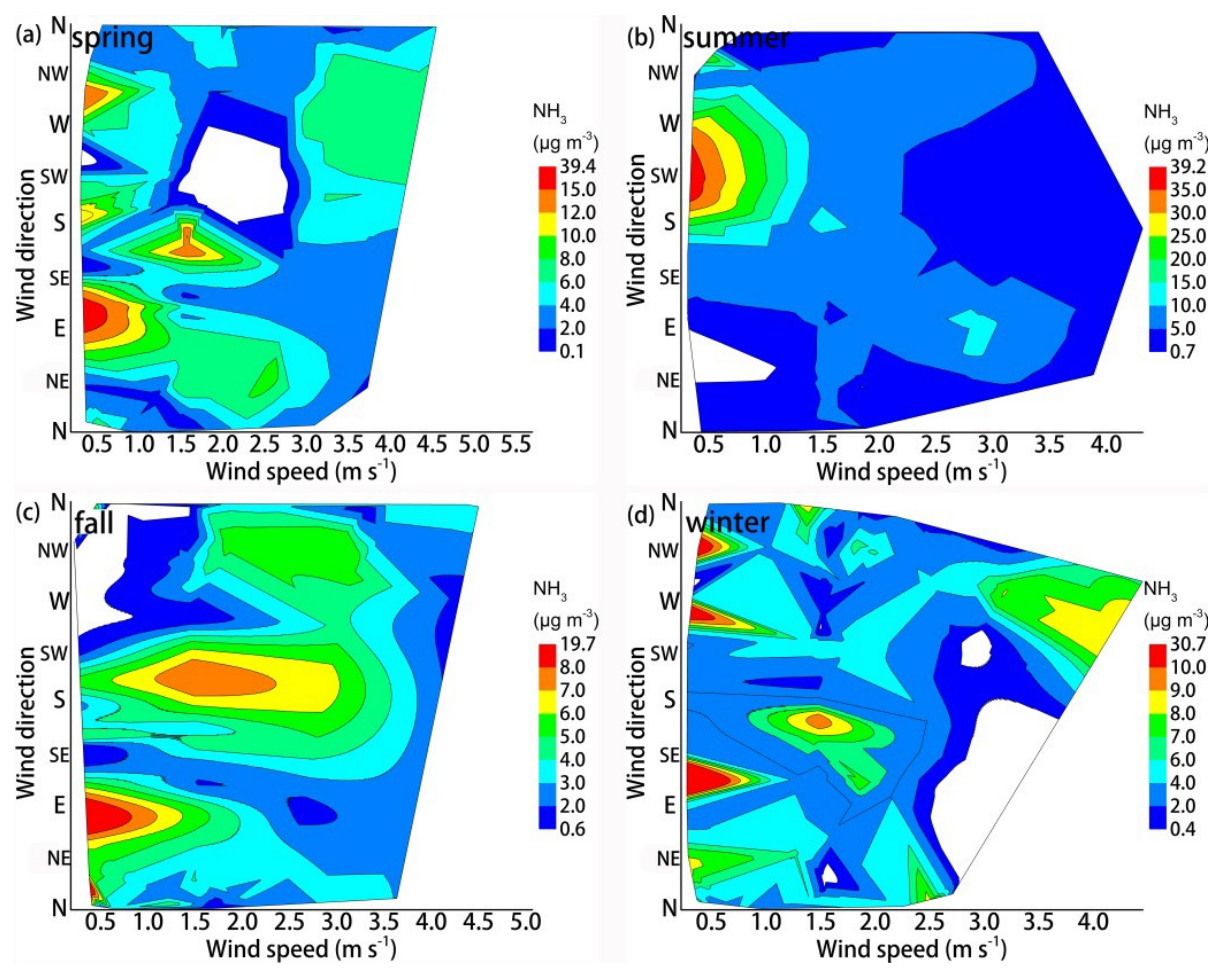

Figure S3. WS/WD dependence of $\mathrm{NH}_{3}$ concentrations in spring (a), summer (b), fall (c), and winter (d) at Pudong supersite during April 2, 2014-April 3, 2015. 


\section{Table}

Table S1. Descriptive statistics of the $\mathrm{NH}_{3}$ concentration $\left(\mu \mathrm{g} \mathrm{m}^{-3}\right)$ at different sampling sites in and out of the Handan Tunnel during the spring campaign in 2014.

See Figure 7a and the method section for the information on the sampling points.

\begin{tabular}{clcccccc}
\hline & Sampling point & $\mathrm{N}$ & Mean & SD & Minimum & Median & Maximum \\
\cline { 2 - 7 } Handan & T-a & 6 & 12.6 & 3.3 & 8.8 & 12.3 & 18.1 \\
Tunnel & $\mathrm{T}-\mathrm{b}$ & 6 & 29.2 & 6.6 & 20.1 & 28.6 & 38.7 \\
& $\mathrm{~T}-\mathrm{c}$ & 6 & 31.5 & 5.9 & 21.4 & 33.3 & 37.6 \\
& $\mathrm{~T}-\mathrm{d}$ & 19 & 64.9 & 11.5 & 47.0 & 65.4 & 82.9 \\
\hline \multirow{5}{*}{ Open } & $\mathrm{O}_{0 \mathrm{~m}}$ & 19 & 11.7 & 4.2 & 7.5 & 10.7 & 25.0 \\
& $\mathrm{O}_{20 \mathrm{~m}}$ & 19 & 6.5 & 2.8 & 2.8 & 5.8 & 13.2 \\
environment & $\mathrm{O}_{150 \mathrm{~m}}$ & 19 & 5.9 & 2.5 & 2.1 & 5.1 & 10.7 \\
& $\mathrm{O}_{310 \mathrm{~m}}$ & 19 & 5.6 & 2.5 & 1.9 & 4.9 & 10.1 \\
\hline
\end{tabular}

